\title{
The development of a national nutrition and mental health research agenda with comparison of priorities among diverse stakeholders
}

\author{
Karen M Davison ${ }^{1,2, *}$, Carla D'Andreamatteo ${ }^{3}$, Scott Mitchell ${ }^{4}$ and Pat Vanderkooy ${ }^{3}$ \\ ${ }^{1}$ School of Nursing, University of British Columbia, Vancouver, British Columbia, Canada: ${ }^{2}$ Health Science Program, \\ Department of Biology, Kwantlen Polytechnic University, Fir Building Room 339, 12666 72nd Avenue, Surrey, British \\ Columbia, Canada, V3W 2M8: ${ }^{3}$ Dietitians of Canada, Toronto, Ontario, Canada: ${ }^{4}$ Canadian Mental Health \\ Association (Ontario), Toronto, Ontario, Canada
}

Submitted 7 May 2016: Final revision received 21 June 2016: Accepted 29 June 2016: First published online 16 January 2017

\begin{abstract}
Objective: To develop a national nutrition and mental health research agenda based on the engagement of diverse stakeholders and to assess research priorities by stakeholder groups.

Design: A staged, integrated and participatory initiative was implemented to structure a national nutrition and mental health research agenda that included: (i) national stakeholder consultations to prioritize research questions; (ii) a workshop involving national representatives from research, policy and practice to further define priorities; (iii) triangulation of data to formulate the agenda; and (iv) test hypotheses about stakeholder influences on decision making.

Setting: Canada.

Subjects: Diverse stakeholders including researchers, academics, administrators, service providers, policy makers, practitioners, non-profit, industry and funding agency representatives, front-line workers, individuals with lived experience of a mental health condition and those who provide care for them.

Results: This first-of-its-kind research priority-setting initiative showed points of agreement among diverse stakeholders ( $n$ 899) on research priorities aimed at service provision; however, respondents with lived experience of a mental health condition (themselves or a family member) placed emphasis on prevention and mental health promotion-based research. The final integrated agenda identified four research priorities, including programmes and services, service provider roles, the determinants of health and knowledge translation and exchange. These research priorities aim to identify effective models of care, enhance collaboration, inform policy makers and foster knowledge dissemination.

Conclusions: Since a predictor of research uptake is the involvement of relevant stakeholders, a sustained and deliberate effort must continue to engage collaboration that will lead to the optimization of nutrition and mental healthrelated outcomes.
\end{abstract}

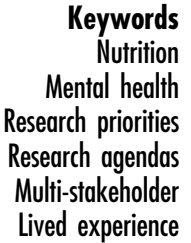

Nutrition

Mental health Research agendas Multi-stakeholder Lived experience
Nutrition interventions are integral in mental health promotion and mental illness prevention, treatment and rehabilitation $^{(1)}$. In recent years, there has been substantial progress in nutrition and mental health research that has coincided with increased worldwide attention ${ }^{(2)}$. However, across disciplines including nutrition and mental health, gaps continue to exist between research, health priorities, policy and practice ${ }^{(3-6)}$.

Nutrition and mental health intersect in many ways ${ }^{(7)}$. Medical nutrition therapy is a cornerstone in psychiatric treatment that can help optimize the structure and function of neurons and brain centres. Furthermore, nutritional interventions as part of integrated programmes foster social inclusion, self-reliance, food security and healthy body image, as well as health and social equities. Given that a substantial portion of the global burden of disease is attributable to mental health conditions ${ }^{(8,9)}$ and that diet is the leading risk factor of the global burden of disease ${ }^{(10)}$, integrated nutrition and mental health research directives are needed to advance mental health.

While there is a need to engage diverse stakeholders to define research priorities, currently no collaborative 
nutrition and mental health research agendas exist. In 2009, the Lancet Mental Health Group set priorities for global mental health that identified what health policy and systems research was needed to examine the effects of integration of management of child and adolescent mental disorders with physical diseases, including poor nutrition $^{(11)}$. The International Society for Nutritional Psychiatry Research completed a Delphi process to inform a consensus statement from experts and stakeholders with an interest in nutritional psychiatry to help guide research, clinical guidelines and public policy ${ }^{(12)}$.

In the development of research priorities, several challenges have been identified. While some issues that have global impacts merit the development of international investigative agendas, the research outcomes may not adequately address health problems in a given country $^{(4)}$. Second, many agenda-setting processes tend to use single methods that involve funders and scientists with little input from policy makers and those with experiential knowledge, which limits exploration of differing perspectives, is subject to expert opinion bias and can result in specious consensus with limited external validity ${ }^{(11,13-15)}$. Conversely, the use of mixed methods and the engagement of diverse groups recognizes the importance of experiential knowledge and ultimately creates results that are more likely to be used to improve the system ${ }^{(16-19)}$.

In recent years, funding bodies have emphasized the importance of citizen engagement (i.e. meaningful involvement of individual citizens in research, planning and implementation) in research and policy development ${ }^{(20,21)}$. 'Citizens' include interested representatives from the general public, consumers of health services, patients, caregivers, advocates, affected communities and voluntary health organizations ${ }^{(21)}$. Although citizen engagement is integral to planning processes, little is known about its influence in higher-level decision making. To align with the evidence that early and continued involvement of stakeholders predicts research uptake ${ }^{(18,21,22)}$, we instituted an integrated, citizen-engaged, mixed-methods initiative to establish a Canadian nutrition and mental health research agenda that aimed to: (i) include diverse stakeholders; (ii) identify specific research criteria and priorities to form a coherent nutrition and mental health investigative strategy; (iii) foster collaborations and knowledge mobilization; and (iv) test hypotheses about stakeholder characteristics and research prioritization.

\section{Method}

\section{The Canadian community mental health system}

To understand contextual factors that help shape the research agenda, one must understand the Canadian mental health system (includes ten provinces and three territories) which comprises the following characteristics ${ }^{(23)}$ : (i) a mix of institution-based services delivered by unionized professionals and non-unionized voluntary-sector providers; (ii) universal coverage of hospital and physician (including psychiatry services) and voluntary-sector providers, but not allied health professionals (e.g. dietitians, psychologists) with independent practices; and (iii) regionalized care delivery (in most provinces) that results in differentiation of community mental health services. In addition, several philosophies guide practice that include ${ }^{(24-31)}$ : (i) team-based care that provides rehabilitation and recovery services and offers integrated interventions (e.g. medical, housing, financial, vocational, social) to individuals with high needs; (ii) recovery movements that emphasize participation of peer support workers within services, self-determination, respectful and collaborative partnerships, and consumer-operated programmes; (iii) recognition of historical neglect that has led to goals in providing comprehensive, team-based care to mitigate suffering to affected individuals, families and communities ${ }^{(26-30)}$; and (iv) evidence-based practices that includes ongoing front-line staff and team leaders' training and highquality services ${ }^{(30,31)}$. Among mental health stakeholders, the philosophy that people with lived experience of a mental health condition should participate in research and administrative decisions is increasingly common.

\section{Nutrition and mental bealtb research agenda- setting processes}

The nutrition and mental health research agenda development project was a collaborative effort of the Canadian Mental Health Association (Ontario), Dietitians of Canada and the University of British Columbia. Representatives from each of these agencies and institutions as well as a hired project coordinator formed the core working group. A detailed project report, including measurement tools, is available ${ }^{(32)}$.

The agenda-setting process included a multistep, participatory and mixed-methods approach to solicit, structure and prioritize investigative themes from diverse stakeholders. Complementary opportunities for participating included in-person, online and telephone-based methods that helped ensure robust representation.

\section{Formation of an advisory group and scoping review}

To act as expert consultants to the core working group, a nine-member national advisory committee was convened that included representatives from public health, dietetics, psychiatry, research, knowledge translation, policy, government and food systems that provided direction on identifying and recruiting participants, structuring core concepts, as well as data collection, analysis and reporting processes.

A scoping review was conducted to synthesize a wide range of nutrition and mental health literature to facilitate the development of research questions ${ }^{(33,34)}$. The scoping 
review followed from a literature synthesis about nutrition and mental health completed in December $2012^{(7)}$ and included nutrition investigations and programmes that related to conditions outlined in the American Psychiatric Association's Diagnostic and Statistical Manual of Mental Disorders, Fifth Edition (DSM-V) ${ }^{(35)}$. The information was located by a structured literature review of databases (Medline, PsychInfo, Cumulative Index to Nursing and Allied Health Literature, Allied and Complementary Medicine) including studies since 2006, followed by citation searches, locating grey literature from government and agencies (e.g. Mental Health Commission of Canada, WHO) and contacting different stakeholders about current initiatives. All relevant sources were categorized by country/area, individuals involved, description of the programme or study (e.g. method), and main results or outcomes.

\section{Stakebolder consultation}

National stakeholder online survey: development and description. Results of the scoping review helped shape the research questions to include in the national online stakeholder survey. The questionnaire incorporated the principles of web-based survey development ${ }^{(36)}$ and was administered using FluidSurveys ${ }^{\mathrm{TM}(37)}$. Efforts were made to create a survey that was understood by a diverse range of stakeholders. The development process was guided by the advisory committee, two stakeholder interviews (an individual with lived experience of a mental health condition and a social worker working in mental health services) and pilot work with five individuals (allied health professionals and individuals with lived experience) to ensure all understood the research questions.

The survey was comprised of four main sections. The first component included questions about demographics (e.g. age, sex, region) and stakeholder group. In the second part of the survey, respondents were asked to specify among a list of mental health conditions (e.g. anxiety, autism spectrum, attention deficit hyperactivity, bipolar, depressive, eating, neurocognitive, neurodevelopment, schizophrenia spectrum, substance use/addictions, and trauma and stressor-related disorders) the ones that should be prioritized for research. In the next section, respondents chose research priorities among a list of special populations (i.e. children and youth, First Nations, Inuit and Metis, homeless or marginally housed, newcomers to Canada, older adults, persons living in remote or rural locations, persons living in a group home or institution, persons living with a developmental disability, women in the perinatal period).

In the fourth section, participants prioritized research questions based on a two-stage process. First, the research questions were presented in three categories that included queries related to: (i) improving the health of people living with mental health conditions (five questions); (ii) improving community nutrition and mental health programmes and services (seven questions); and (iii) promoting mental health and/or preventing or delaying the onset of mental health conditions (three questions). Participants were then asked to indicate how important they thought it was for researchers to address the research questions outlined using a five-point Likerttype scale of importance (i.e. range from 'very important' to 'not important') and an option to provide 'no opinion'. They were then asked to select the one research question they thought was the most important within each of the three categories. As a final prioritizing step, all research questions from the three categories were presented and participants were asked to select the top three they believed would have the greatest impact on nutrition and mental health. Throughout the survey, respondents were given open-ended questions designed to elicit feedback about other research questions that should be included, the rationale for their research question selections, the agenda-setting process and suggestions of stakeholders that should be consulted for in-depth interviews.

National stakebolder online survey: dissemination. The online survey was nationally disseminated for six weeks to the extensive network generated by the advisory committee. Potential participants were made aware of the survey through direct email notifications and advertisements through relevant media channels (e.g. Twitter, LinkedIn, electronic newsletters). In addition, a snowball approach was used where survey participants were encouraged to actively engage other interested parties. During the data collection period, responses were carefully monitored to ensure representation from various stakeholders.

National stakeholder online survey: analysis. Data quality was verified by checking for duplication of Internet Protocol addresses and conducting cross-tabulations of related variables (e.g. indicated years of practice with respondent age). The survey results were analysed using descriptive statistics (e.g. frequencies, means). To test hypotheses related to participant characteristics and research prioritization, inferential analysis according to stakeholder subgroups and research questions was conducted using binomial tests of two proportions, $\chi^{2}$ and Fisher exact statistics.

Key informant consultation. The online survey participants provided more than 100 stakeholder contacts that the advisory committee reviewed. Nine key informants representing all stakeholder groups were identified and interviews were conducted to explore emergent concepts about nutrition and mental health research and to identify divergent perspectives. The telephone-based interviews were semi-structured, lasted about $30 \mathrm{~min}$ and were conducted by the project coordinator. During the interviews, participants were asked to reflect on the priority research areas and rankings from the national online survey. Interviews were recorded (with consent) and transcribed by two transcription service providers. The transcripts' texts were analysed using thematic analyses ${ }^{(38)}$. 
For the remaining key informant contacts with complete information ( $n$ 105), an online questionnaire was distributed. The survey included questions about demographics, stakeholder group affiliation, barriers to uptake of research findings, potential funders and research partners, as well as perspectives on knowledge dissemination.

The main intent of the key informant consultations was to help identify criteria for establishing nutrition and mental health research priorities that would be used in the national workshop. As part of the scoping review, an extensive search was conducted to locate research priority-setting approaches and a final list of criteria was derived based on those used by the Council on Health Research for Development ${ }^{(39)}$. An electronic invitation to complete the questionnaire was distributed to the key informants and was active during December 2013.

\section{Research agenda formulation}

After integrating the data from the scoping review, online stakeholder survey and key informant consultations, potential research topics and questions were formulated to present to a defined diverse group of sixteen stakeholders at a national workshop held in Toronto, Ontario in February 2014. The workshop objectives included: (i) reaffirming the elements of nutrition and mental health research, including guiding principles; (ii) reaching consensus on Canadian nutrition and mental health research priorities; and (iii) discussing strategies to implement the research agenda. Prior to the workshop, participants were given background readings (i.e. scoping review, survey results) to facilitate their understanding of current directions in Canadian nutrition and mental health research and project objectives.

During the workshop, a variety of formats were used to enable egalitarian and meaningful dialogue, including brief didactic presentations, small group work, facilitated group discussions, a criteria-setting task and brainstorming exercises. The priority-setting exercise included work in small groups to establish a priority rating for each of the nutrition and mental health research questions, utilizing criteria categories defined from the key informant consultation. Workshop participants then reviewed the results of the priority-setting exercise and had small and large group dialogues about the current Canadian nutrition and mental health context and how the outcomes of the defined research agenda may be implemented to inform current practice, policy and research. As a final step, participants were asked to complete a workshop evaluation.

The final analysis involved synthesizing the research priorities from the multistep process that included drawing upon thematic analysis from the textual data, integrating these themes with the information from the scoping review and quantitative survey data, and examining associations between stakeholder types and research priorities. Using a triangulation design model, quantitative and qualitative data were first analysed independently (in parallel) and then discussed among the core team to achieve concurrent triangulation ${ }^{(17)}$.

\section{Results}

\section{Scoping review}

The scoping review resulted in the development of a document ${ }^{(40)}$ that detailed current community and clinicalbased mental health research, programmes and services, and collaborations in Canada and internationally. The review provided evidence that supports the many links that exist between food and nutrient intake and mental health. However, these findings need to be translated to community settings and their impact on mental health assessed. Results of the scoping review also highlighted how community-level nutrition programming related to mental health varies across Canada; most were embedded within larger initiatives, with nutrition interventions being a subset of the curriculum. In summary, the review identified a need for more nutrition and mental health research in areas such as health promotion, prevention, intervention and rehabilitation as a means to develop programming and policy.

\section{National consultation}

\section{National stakeholder online survey}

Online survey respondents (Table 1) were all adults (aged 18 years or older) and from all regions and stakeholder groups. Of the 811 participants, most respondents (89\%) were female and between the ages of 18 and 59 years (88\%). Although there was some variation among the stakeholder groups, the main mental health conditionspecific research priorities identified included depression ( $n 712,88 \%$ ), anxiety ( $n$ 640, 79\%) and disordered eating ( $n$ 628, $77 \%$ ). Pregnancy-related mental health conditions were added by some ( $n$ 28, 3\%) as another research priority. The majority of respondents indicated that children and youth ( $n$ 470, 58\%) were top priority; however, more than half of the participants ( $n$ 411, $51 \%)$ also identified that all population groups were equally important. Individuals with limited income were added by about $3 \%$ of respondents $(n$ 29) as a population group that requires higher priority.

The pooled results indicated that the top three research questions were: (i) 'How does food and/or nutrient intake affect specific mental health conditions?'; (ii) 'How do life situations (e.g. housing, income, education, employment) affect the type and amount of food that people eat and what impact does that have on their mental health?'; and (iii) 'What programmes or services do people living with mental health conditions need with respect to food access, nutrition and/or cooking skills?'. There were some differences among the stakeholder groups (Table 2). As examples, dietitians and managers selected research questions related to food skills training, managers also 
Table 1 Characteristics of national online survey respondents and key informants in an integrated, citizen-engaged, mixed-methods initiative to establish a Canadian nutrition and mental health research agenda

\begin{tabular}{|c|c|c|c|c|c|c|c|c|c|c|c|c|}
\hline \multirow[b]{3}{*}{ Characteristic } & \multicolumn{6}{|c|}{ Online survey participants } & \multicolumn{6}{|c|}{ Key informant participants } \\
\hline & \multicolumn{2}{|c|}{$\begin{array}{c}\text { Total } \\
(n \text { 811) }\end{array}$} & \multicolumn{2}{|c|}{$\begin{array}{c}\text { LE† } \\
(n \text { 244) }\end{array}$} & \multicolumn{2}{|c|}{$\begin{array}{c}\text { FMł } \\
(n \text { 344) }\end{array}$} & \multicolumn{2}{|c|}{$\begin{array}{c}\text { Total } \\
(n 63)\end{array}$} & \multicolumn{2}{|c|}{$\begin{array}{l}\text { LE† } \\
(n \text { 30) }\end{array}$} & \multicolumn{2}{|c|}{$\begin{array}{c}\text { FM } \\
(n 36)\end{array}$} \\
\hline & $n$ & $\% \S$ & $n$ & $\% \S$ & $n$ & $\% \S$ & $n$ & $\% \S$ & $n$ & $\% \S$ & $n$ & $\% \S$ \\
\hline \multicolumn{13}{|l|}{ 1. Regions (total responses: $n 793$ for online survey; $n 62$ for key informant participants) } \\
\hline British Columbia plus Yukon & 134 & 17 & 56 & 23 & 65 & 19 & 16 & 25 & 10 & 33 & 11 & 31 \\
\hline Alberta, Saskatchewan, Manitoba, Northwest Territories, Nunavut & 177 & 22 & 50 & 20 & 76 & 22 & 9 & 14 & 7 & 23 & 6 & 17 \\
\hline Ontario & 414 & 51 & 113 & 46 & 158 & 46 & 32 & 51 & 12 & 40 & 17 & 47 \\
\hline $\begin{array}{l}\text { Quebec, New Brunswick, Newfoundland and Labrador, Nova Scotia, Prince Edward Island } \\
\text { 2. Community size (total responses: } n 807 \text { for online survey; } n 63 \text { for key informant participants) }\end{array}$ & 68 & 8 & 19 & 8 & 34 & 10 & 5 & 8 & 2 & 7 & 2 & 6 \\
\hline 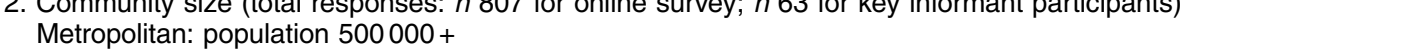 & 218 & 27 & 66 & 27 & 93 & 27 & 23 & 37 & 10 & 33 & 14 & 39 \\
\hline Large city: population 100000 to 499999 & 231 & 28 & 77 & 32 & 98 & 28 & 15 & 24 & 5 & 17 & 6 & 17 \\
\hline Medium city: population 30000 to 99999 & 157 & 19 & 44 & 18 & 67 & 19 & 10 & 16 & 7 & 23 & 7 & 19 \\
\hline Small city, towns, villages and rural areas: population $\leq 29999$ & 201 & 24 & 54 & 22 & 82 & 24 & 15 & 24 & 8 & 27 & 9 & 25 \\
\hline \multicolumn{13}{|c|}{ 3. Stakeholder groupsIl (total responses: $n 811$ for online survey; $n 63$ for key informant consultations. Respondents could select $\geq 1$ category) } \\
\hline Service provider & 433 & 53 & 138 & 57 & 186 & 54 & 37 & 59 & 16 & 53 & 22 & 61 \\
\hline Registered dietitian (includes community, clinical, administrative) & 299 & 37 & 55 & 23 & 116 & 34 & 25 & 40 & 8 & 27 & 13 & 36 \\
\hline Advocacy work related to mental health & 135 & 17 & 59 & 24 & 92 & 27 & 14 & 22 & 9 & 30 & 11 & 31 \\
\hline Volunteer in a nutrition and/or mental health setting & 120 & 15 & 61 & 25 & 77 & 22 & 16 & 25 & 14 & 47 & 12 & 33 \\
\hline Researcher in nutrition and/or mental health research (includes academic, clinical and independent consultants) & 109 & 13 & 36 & 15 & 53 & 15 & 18 & 29 & 10 & 33 & 11 & 31 \\
\hline 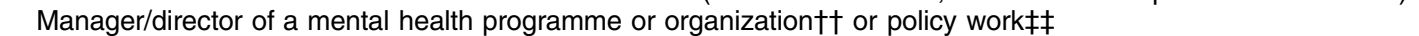 & 118 & 15 & 40 & 16 & 63 & 18 & 6 & 10 & 5 & 17 & 5 & 14 \\
\hline Lived experience of a mental health condition & 244 & 30 & - & - & 154 & 45 & 30 & 48 & - & - & 22 & 61 \\
\hline Family member of someone with a lived experience of a mental health condition(s) & 344 & 42 & 154 & 63 & - & - & 36 & 57 & 22 & 73 & - & - \\
\hline
\end{tabular}

\section{tLived experience.}

fFamily member with lived experience.

Percentages reported used column total as denominator.

IThere were seventeen respondents who indicated their stakeholder role was as a post-secondary student; due to the small sample size subgroup analysis was not conducted on this group. Stakeholder totals are greater than sample total as respondents could select all groups they identified with.

TRespondents indicated their service provider roles included nurse (RN, LPN, NP), support/peer support worker, counsellor, psychologist, psychometrist and social worker.

††Respondents indicated their manager/director roles included programmes and services, executive director, patient/client care, social worker and behavioural therapy.

¥Working or have worked in public policy: public policy roles included public health professional, health promoter, policy analyst and health adviser. 


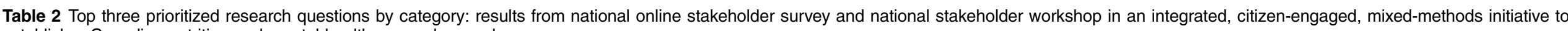
establish a Canadian nutrition and mental health research agenda

Rank $(\mathrm{R})$ and percentage (\%) of total for indicated category by participant-defined stakeholder group $\dagger$

\begin{tabular}{|c|c|c|c|c|c|c|c|c|c|c|c|c|c|c|c|c|c|c|c|c|c|c|c|c|c|c|c|c|c|c|c|}
\hline \multicolumn{5}{|c|}{ Service provider $\ddagger$} & \multicolumn{4}{|c|}{ Registered dietitian } & \multicolumn{5}{|c|}{ Advocacy§ } & \multicolumn{4}{|c|}{ Volunteerll } & \multicolumn{5}{|c|}{ Researcher } & \multicolumn{5}{|c|}{ Manager/director†† } & \multicolumn{3}{|c|}{ Public policyłł } & \multirow[b]{2}{*}{$\begin{array}{l}\text { LEß§§ } \\
(n 51)\end{array}$} \\
\hline $\begin{array}{c}\mathrm{T} \\
n \text { 433) }\end{array}$ & $\begin{array}{r}\mathrm{L} \\
(n 1\end{array}$ & & $\begin{array}{r}\mathrm{FM} \\
\text { (n } 18\end{array}$ & & $\begin{array}{c}\mathrm{T} \\
(n \text { 299) }\end{array}$ & $\begin{array}{c}\text { LE } \\
\text { (n } 55\end{array}$ & & $\begin{array}{l}F M \\
116)\end{array}$ & $\begin{array}{r}\mathrm{T} \\
\text { (n } 1\end{array}$ & & $\begin{array}{c}\text { LE } \\
(n 59)\end{array}$ & & & $\begin{array}{c}\mathrm{T} \\
(n 120)\end{array}$ & & & $\begin{array}{c}\mathrm{FM} \\
(n \text { 77) }\end{array}$ & & & & & $\begin{array}{c}\mathrm{FM} \\
(n \text { 53) }\end{array}$ & $\begin{array}{c}\mathrm{T} \\
(n 70)\end{array}$ & & & & & & & $\begin{array}{c}\text { LE } \\
(n 17)\end{array}$ & \\
\hline
\end{tabular}

Category 1: Research questions aimed to improve the health of people living with mental health conditions (4 of 5 questions total ranked in the top 3 )

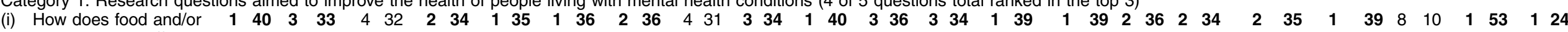
nutrient intake affect specific MHC?

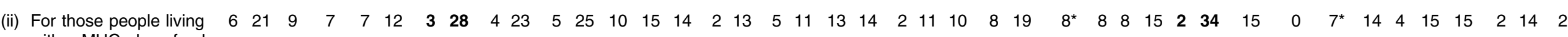
with a MHC, does food skills training||l| have an impact on their mental health?

(iii) How do life $\begin{array}{lllllllllllllllllllllllllllllllllllllllllllllll}3 & 30 & 2 & 42 & 2 & 37 & 4 & 26 & 3 & 29 & 4 & 28 & 1 & 42 & 1 & 51 & 2 & 39 & 3 & 32 & 1 & 46 & 2 & 38 & 3 & 32 & 4 & 28 & 4 & 26 & 3 & 33 & 1 & 43 & 5 & 28 & 1 & 40 & 7 & 6 & 7 & 8\end{array}$ situations If affect the type and amount of food that people eat and what impact does that have on their mental health?

(iv) What food-related policies would help people living with a MHC?

Category 2: Research questions aimed to improve community nutrition and mental health programmes and services ( 3 of 7 questions total ranked in top 3 )

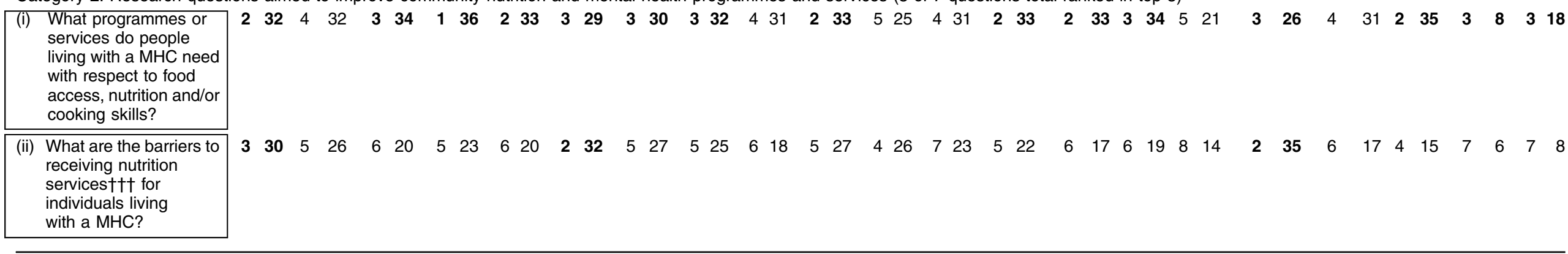


Rank $(R)$ and percentage $(\%)$ of total for indicated category by participant-defined stakeholder groupt

\begin{tabular}{|c|c|c|c|c|c|c|c|c|c|c|c|c|c|c|c|c|c|c|c|c|c|c|c|c|c|c|c|c|c|c|c|c|c|c|c|c|c|c|c|c|c|c|c|}
\hline \multirow[b]{3}{*}{ Research question } & \multicolumn{6}{|c|}{ Service providerł } & \multicolumn{6}{|c|}{ Registered dietitian } & \multicolumn{6}{|c|}{ Advocacy§ } & \multicolumn{6}{|c|}{ Volunteerll } & \multicolumn{6}{|c|}{ Researcher } & \multicolumn{7}{|c|}{ Manager/director†† } & \multicolumn{4}{|c|}{ Public policy $\ddagger \ddagger$} & \multirow{2}{*}{\multicolumn{2}{|c|}{$\begin{array}{l}\text { LEß§ } \\
(n 51)\end{array}$}} \\
\hline & \multicolumn{2}{|c|}{$\begin{array}{c}\mathrm{T} \\
(n+33)\end{array}$} & \multicolumn{2}{|c|}{$\begin{array}{c}\mathrm{LE} \\
(n 138)\end{array}$} & \multicolumn{2}{|c|}{$\begin{array}{c}\text { FM } \\
(n \text { 186) }\end{array}$} & \multicolumn{2}{|c|}{$\begin{array}{c}\mathrm{T} \\
(n 299)\end{array}$} & \multicolumn{2}{|c|}{$\begin{array}{c}\mathrm{LE} \\
(n 55)\end{array}$} & \multicolumn{2}{|c|}{$\begin{array}{c}\mathrm{FM} \\
(n 116)\end{array}$} & \multicolumn{2}{|c|}{$\begin{array}{c}\mathrm{T} \\
\left(\begin{array}{l}n \\
135\end{array}\right)\end{array}$} & \multicolumn{2}{|c|}{$\begin{array}{c}\mathrm{LE} \\
(n 59) \\
\end{array}$} & \multicolumn{2}{|c|}{$\begin{array}{c}\mathrm{FM} \\
(n \text { 92) } \\
\end{array}$} & \multicolumn{2}{|c|}{$\begin{array}{c}\mathrm{T} \\
(n \mathrm{120})\end{array}$} & \multicolumn{2}{|c|}{$\begin{array}{c}\mathrm{LE} \\
(n 61) \\
\end{array}$} & \multicolumn{2}{|c|}{$\begin{array}{c}\mathrm{FM} \\
(n 77)\end{array}$} & \multicolumn{2}{|c|}{$\begin{array}{c}\mathrm{T} \\
\left(\begin{array}{c}n \\
109\end{array}\right)\end{array}$} & \multicolumn{2}{|c|}{$\begin{array}{l}\text { LE } \\
(n 36)\end{array}$} & \multicolumn{2}{|c|}{$\begin{array}{c}\text { FM } \\
(n 53) \\
\end{array}$} & & $\begin{array}{c}\mathrm{T} \\
(n 70) \\
\end{array}$ & $\begin{array}{l}\text { LE } \\
(n 2\end{array}$ & & & $\begin{array}{l}\text { FM } \\
n \text { 36) }\end{array}$ & & $\left(n^{\top}\right.$ & ए & $\stackrel{\mathrm{L}}{(n}$ & $\begin{array}{l}E \\
17)\end{array}$ & & \\
\hline & $\mathrm{R}$ & $\%$ & $\mathrm{R}$ & $\%$ & $\mathrm{R}$ & $\%$ & $\mathrm{R}$ & $\%$ & $\mathrm{R}$ & $\%$ & $\mathrm{R}$ & $\%$ & $\mathrm{R}$ & $\%$ & $\mathrm{R}$ & $\%$ & $\mathrm{R}$ & $\%$ & $\mathrm{R}$ & $\%$ & $\mathrm{R}$ & $\%$ & $\mathrm{R}$ & $\%$ & $\mathrm{R}$ & $\%$ & $\mathrm{R}$ & $\%$ & $R$ & $\%$ & & R \% & $\mathrm{R}$ & $\%$ & P & & $\%$ & $\mathrm{R}$ & $\%$ & $\mathrm{R}$ & $\%$ & $\mathrm{R}$ & \% \% \\
\hline $\begin{array}{l}\text { (iii) What are the roles of } \\
\text { non-dietitian service } \\
\text { providers for providing } \\
\text { nutrition information or } \\
\text { support to clients who } \\
\text { are living with a MHC? }\end{array}$ & 14 & 8 & 8 & 9 & 10 & 11 & 15 & 2 & 12 & 7 & 12 & 11 & 14 & 8 & 9 & 10 & 11 & 11 & 14 & 8 & 11 & 13 & 11 & 10 & 12 & 5 & 14 & 3 & 39 & 9 & 91 & 171 & $9^{* *}$ & 4 & & $7^{* *} 1$ & 14 & 9 & 6 & 13 & 4 & & 5 \\
\hline $\begin{array}{l}\text { Category 3: Research ques } \\
\text { (i) How does a healthy } \\
\text { diet and/or access to } \\
\text { healthy food promote } \\
\text { mental health? }\end{array}$ & $\begin{array}{c}\text { tions } \\
7\end{array}$ & aim & ned $t$ & $\begin{array}{l}\text { o pr } \\
44\end{array}$ & $\begin{array}{c}\text { omot } \\
1\end{array}$ & te $m$ & $\begin{array}{c}\text { ental } \\
9\end{array}$ & $\begin{array}{l}\text { I hea } \\
17\end{array}$ & $\begin{array}{c}\text { alth a } \\
7\end{array}$ & $\begin{array}{c}a n d / c \\
18\end{array}$ & $\begin{array}{l}\text { or pr } \\
9\end{array}$ & $\begin{array}{c}\text { ever } \\
20\end{array}$ & $\begin{array}{l}\text { nt or } \\
6\end{array}$ & $\begin{array}{c}\text { dela } \\
23\end{array}$ & $\begin{array}{l}\text { ay th } \\
2\end{array}$ & $\begin{array}{l}\text { ne on } \\
47\end{array}$ & $\begin{array}{r}\text { nset } \\
1\end{array}$ & $\begin{array}{l}\text { of } m \\
45\end{array}$ & $\begin{array}{c}\text { mente } \\
4\end{array}$ & $\begin{array}{c}\text { al he } \\
28\end{array}$ & $\begin{array}{c}\text { ealth } \\
2\end{array}$ & $\begin{array}{l}\text { conc } \\
41\end{array}$ & & $\begin{array}{c}\text { ons ( } \\
42\end{array}$ & (2 of & $\begin{array}{l}3 q u \\
21\end{array}$ & $\begin{array}{r}\text { estic } \\
3\end{array}$ & $\begin{array}{l}\text { ons tc } \\
31\end{array}$ & $\begin{array}{c}\text { total } \\
1\end{array}$ & rar & & $\begin{array}{l}\text { ed in tc } \\
521\end{array}$ & $\begin{array}{l}3) \\
3\end{array}$ & 26 & 3 & & 33 & 8 & 10 & 2 & 10 & & 220 \\
\hline $\begin{array}{l}\text { (ii) How do intakes of } \\
\text { certain foods and/or } \\
\text { nutrients prevent or } \\
\text { delay the onset } \\
\text { of MHC? }\end{array}$ & 8 & 19 & 6 & 14 & 5 & 24 & 8 & 18 & 7 & 18 & 7 & 24 & 9 & 16 & 5 & 25 & 5 & 29 & 7 & 23 & 6 & 23 & 5 & 27 & 10 & 16 & 4 & 28 & 35 & 25 & & $4 \quad 24$ & 1 & 43 & 2 & & 36 & 3 & 23 & 3 & 8 & 4 & $4 \quad 12$ \\
\hline
\end{tabular}

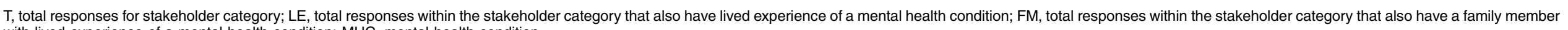
with lived experience of a mental health condition; MHC, mental health condition

with lived expenien

Research question cells with heavy line borders represent the top three research priorities identified at the national workshop; questions 2(i) and 2(iii) had equal scoring.

Significant differences in the proportion of respondents in this group compared with those in the primary identified stakeholder category: ${ }^{\star} P<0.05,{ }^{\star \star} P<0.001$.

totals of stakeholder groups may differ as some indicated more than one type.

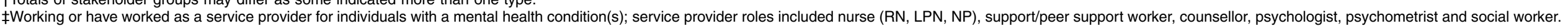
$\S$ Working or have worked in advocacy related to mental health.

SWorking or have worked in advocacy related to mential healh.

TWorking or have worked in nutrition and/or mental health research; researcher roles included academia, clinical research and research consultation.

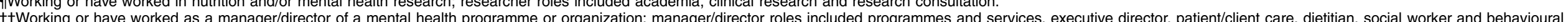

therapy.

\#¥Working or have worked in public policy; public policy roles included public health profession

IIIIExamples: counselling, cooking programmes.

If Housing, income, education, employment.

†††Examples: diabetes, heart disease. 
Table 3 Original criteria ranked by key informants and finalized criteria for national workshop prioritizing exercises in an integrated, citizenengaged, mixed-methods initiative to establish a Canadian nutrition and mental health research agenda

\begin{tabular}{|c|c|c|c|c|}
\hline \multirow[b]{2}{*}{$\begin{array}{l}\text { Original criteria ranked by } \\
\text { key informants }\end{array}$} & \multicolumn{4}{|c|}{ Criteria developed by advisory committee based on key informant rankings } \\
\hline & $\begin{array}{l}\text { Criteria } \\
\text { category }\end{array}$ & Asks... & Factors to consider & \\
\hline \multirow{4}{*}{$\begin{array}{l}\text { 1. Impact on health } \\
\text { 2. Community concern/ } \\
\text { demand } \\
\text { 3. Applicability of research } \\
\text { outcome } \\
\text { 4. Adequacy of current } \\
\text { knowledge base (avoid } \\
\text { duplication) } \\
\text { 5. Economic impact } \\
\text { 6. Magnitude of the } \\
\text { problem } \\
\text { 7. Partnership building } \\
\text { 8. Feasibility } \\
\text { 9. Ethical acceptability } \\
\text { 10. Relevance } \\
\text { 11. Urgency } \\
\text { 12. Equity focus } \\
\text { 13. Funding support } \\
\text { potential } \\
\text { 14. Political acceptability }\end{array}$} & Appropriateness & Should we do it? & $\begin{array}{l}\text { Ethical and cultural issues } \\
\text { - Ethically and morally } \\
\text { acceptable } \\
\text { - Culturally appropriate } \\
\text { - Non-reliance on food } \\
\text { industry }\end{array}$ & $\begin{array}{l}\text { Availability and adequacy of current } \\
\text { information } \\
\text { - Adequacy of current research-based } \\
\text { information (avoid duplication) } \\
\text { - Availability of pre-existing data }\end{array}$ \\
\hline & Relevancy & $\begin{array}{l}\text { Why should we } \\
\text { do it? }\end{array}$ & $\begin{array}{l}\text { Equity-focused and } \\
\text { community concern/ } \\
\text { demand } \\
\text { - Contribution to better } \\
\text { equity in health } \\
\text { - Serves community } \\
\text { concern/demand } \\
\text { - Broad in scope }\end{array}$ & $\begin{array}{l}\text { Burden of illness (size and severity of } \\
\text { problem) } \\
\text { - Burden of illness } \\
\text { - Magnitude of the issue } \\
\text { - Interconnected with social } \\
\text { determinants of health (poverty, food } \\
\text { insecurity, housing) }\end{array}$ \\
\hline & $\begin{array}{l}\text { Chance of } \\
\text { success }\end{array}$ & Can we do it? & $\begin{array}{l}\text { Capacity of the system to } \\
\text { undertake the research } \\
\text { - Competency } \\
\text { - Infrastructure, } \\
\text { mechanisms } \\
\text { - Support system } \\
\text { - Resources }\end{array}$ & $\begin{array}{l}\text { Cost justification } \\
\text { - Likelihood of partnership building } \\
\text { - Reasonable approach } \\
\text { - Funding potential } \\
\text { - Political acceptability } \\
\text { - Pragmatic }\end{array}$ \\
\hline & $\begin{array}{l}\text { Impact of the } \\
\text { research } \\
\text { outcome }\end{array}$ & $\begin{array}{l}\text { What do } \\
\text { stakeholders } \\
\text { get out of it? }\end{array}$ & $\begin{array}{l}\text { Chances of implementation } \\
\text { of research } \\
\text { recommendations } \\
\text { - Applicability to current } \\
\text { practice } \\
\text { - Forward/upstream } \\
\text { thinking }\end{array}$ & $\begin{array}{l}\text { Reduction of the burden, including costs } \\
\text { and quality of life } \\
\text { - Impact of research on mental health } \\
\text { and quality of life within the population } \\
\text { - Economic impact } \\
\text { - Fiscal rewards for balancing healthy } \\
\text { living and healthy mind }\end{array}$ \\
\hline
\end{tabular}

chose questions about the role of non-dietitian service providers, and public policy stakeholders prioritized research pertaining to food-related policies. For participants with lived experience, the priorities were relatively consistent with the overall group; however, they tended to select more Category 3 (i.e. mental health promotion and illness prevention) research questions. Significant differences between the proportions of those selecting lower-ranked research questions were found for service providers, researchers and managers/directors in the topic areas of food skills training and the roles of non-dietitian service providers.

\section{Key informant interview and survey}

The response rate of the key informant questionnaire was approximately $60 \%$. Participants were primarily from the provinces of Ontario and British Columbia (Table 1). More than $70 \%$ of the participants identified impact on health and community concern/demand as key criteria for setting research priorities and no significant differences among the key informants were found in defining research priorities. Triangulation of the data from key informant interview and survey identified four criteria that were considered most important. After consultation with the advisory committee, the criteria were refined with descriptions to use in priority-setting activities at the national workshop (Table 3).

Nine in-depth, telephone-based, key informant interviews with representatives from management, public policy and service provision (i.e. psychiatry, addiction, pharmacy, occupational therapy) were conducted by the project coordinator during December 2013 and January 2014. The transcribed textual data were categorized in three areas (current gaps in research, priority setting and perceived barriers) and at least two themes were defined within each category (Table 4).

\section{Research agenda formulation}

Workshop participants came from five different provinces representing western, central and eastern regions and included academic researchers, mental health, nutrition and community health-service providers, government, and policy makers. The top research priorities identified from the priority-scoring exercise using the criteria categories (items 3 and 4 had equal scoring) were: (i) "What are the barriers to receiving nutrition services for individuals living with mental health conditions?'; (ii) 'What food-related policies would help people living with mental health 
Table 4 Summary of thematic analysis of key informant interviews $(n 9)$ in an integrated, citizen-engaged, mixed-methods initiative to establish a Canadian nutrition and mental health research agenda

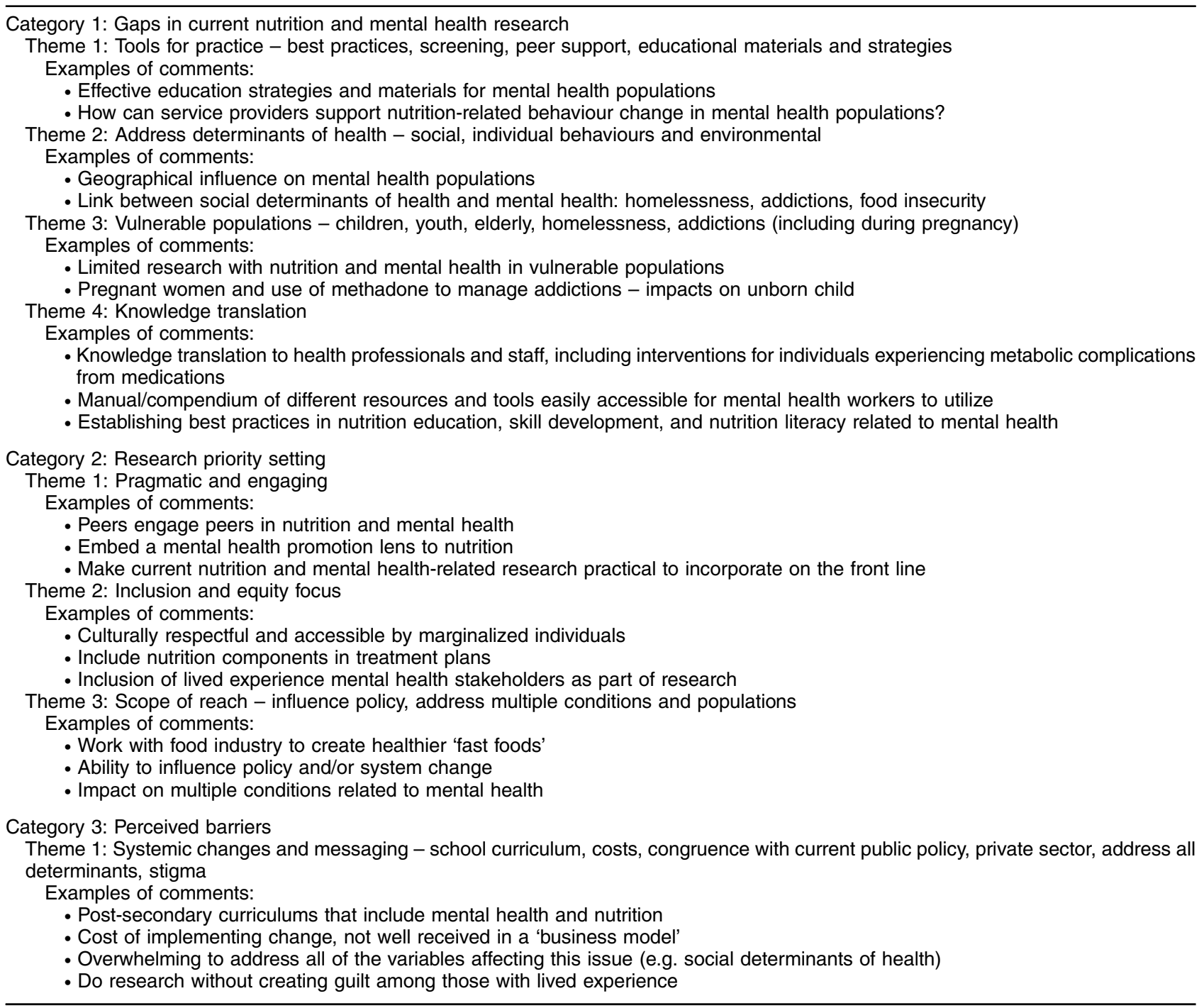

conditions?'; (iii) 'What programmes or services do people living with mental health conditions need with respect to food access, nutrition and/or cooking skills?'; and (iv) 'What are the roles of non-dietitian service providers for providing nutrition information or support to clients who are living with mental health conditions?'. Furthermore, workshop participants extensively discussed how there is a need for more effective knowledge translation and exchange about existing and future nutrition and mental health research.

The evaluations from workshop participants were positive, with a median assessment rating of 4.11 from a range of 0 to 5 . All indicated they had an opportunity to participate and the most useful components of the workshop included discovering what nutrition and mental health research has been done or is in progress, clear tasks and multidisciplinary collaboration. Means in which the workshop could have been more effective included providing the scope of exercises ahead of time and having a second meeting to see how the information from the workshop will be used.

When the top research priorities from the online stakeholder survey (had no criteria) were combined with the priorities identified in the workshop (used specified criteria), all of the investigative gaps identified from the scoping review were included.

The inclusion of those with lived experience in the decision-making process did not significantly alter the research priorities identified (Table 2). However, thematic analysis of the textual data from key informant interviews as well as the online stakeholder and key informant surveys (Tables 4 and 5) provided important insights about research and knowledge dissemination. In particular, those with mental health conditions emphasized the need for research as four key themes (Table 5): (i) applied and pragmatic; (ii) inclusive and equity-focused; (iii) fostering mental 
Table 5 Key themes from participants from textual data (online stakeholder survey, key informant consultation) in an integrated, citizenengaged, mixed-methods initiative to establish a Canadian nutrition and mental health research agenda

Theme 1: Applied and pragmatic

- 'Natural nutritional supplements: the inadequacy of the knowledge base and lack of quality regulation. Some natural supplements may be very helpful, others not. Consumers need reliable information.'

- 'Having research-based data that explains how eating impacts mental health, both positively and negatively, will provide the information needed to motivate government, service providers and those with lived experience (and without) to eat in a way that will benefit them physically and mentally.'

- 'Always, my priorities are to see such research focused on relevance and direct application: follow-through. And the funding and infrastructure to make sure changes first occur and then are ongoing.'

- 'It must be pragmatic, the need is so great and the time was yesterday. Create a plan that has some more immediate implementation, in order to help stakeholders feel that things are happening. Research and a report for the sake of it kills the energy of those in the front line who witness the pain and suffering daily.'

Theme 2: Inclusive and equity-focused

- 'It just needs to be more accessible, promoted, equal and positive. It needs to reach rural and small towns in a way that is not intrusive that meets someone on their level. An example, a single mom with previous mental health concerns subsisting on Ontario Works may not know how to be active and engaged with proper nutrition for their developing child or themselves...'

- 'I would hope that all research would be informed by an overarching concern for - and consultation with - people with lived experience and with families of those with lived experience.'

- 'Food insecurity is, and remains a significant issue for individuals that we serve in our programmes and services. This links directly to the issue of poverty and other social determinants of health. Without understanding these core issues, actions to support nutrition and mental health will be limited in scope.'

- 'Addressing social determinants of health will help to address issues of lack of, access to and education about food and nutrition.'

- 'Poverty, food security and mental health are interconnected. People most impacted have only PWD as an income source and have limited food options as a result.'

- 'I think determining barriers and assessing the impact that the social determinants of health has on a person with a mental health condition is paramount in establishing effective nutrition services for those living with a mental health condition.'

Theme 3: Fostering mental health literacy

- '... I would consider both the individual's perceived benefit, but also exploring the impact of stigma and prejudices and disrespect and how if affects the services that are offered, or not offered to help with meeting nutrition needs.'

- 'To me these three questions are the most important because there is so much stigma that exists for people living with mental illness. Coupling that with other barriers (like limited knowledge, access or understanding of how nutrition plays a role in mental health and mental illness) people living with MI will not learn the benefits of how to flourish in life, even when living with a mental illness.'

- 'I feel weight bias impact on mental health should be included as part or on its own as larger bodied people are often stigmatized which can lead to poor mental health and health behaviours whereas if people received kind, compassionate care free of weight bias, their other mental health issues (if any) would not be amplified.'

- 'Some people seem to fall through the cracks of the system. It is still a stigma, especially in smaller communities.'

- 'Time, money, commitment and the desire to drive change and sustainability in the stigma reduction.'

- 'It is excellent that you are making this type of research a priority. I hope the outcomes will benefit people with lived experience and not stigmatize their families.'

Theme 4: Interdisciplinary and participatory research

- 'One thing does not cure everything, i.e. diet is not the be all end all for everyone.'

- 'While biochemical research and understanding is necessary, there is a need to understand the environment and determinants of mental health that also affect nutritional intakes and access.'

- 'Obesity and mental health (schizophrenia, depression, eating disorder). Two multifactorial disorders requiring interdisciplinary treatment and very common in Canada.

- 'Important to engage community partners in a positive way.'

- 'Please collaborate with consumers as peer researchers with equal control of projects.'

PWD, persons with disabilities; MI, mental illness.

health literacy; and (iv) interdisciplinary investigation. Integration of all of the data sources from this citizenengaged and mixed-methods process led to the articulation of a research agenda (Fig. 1) that defines a set of research criteria, guidelines and four broad investigative priorities that reflects the needs and perspectives of diverse stakeholders.

\section{Discussion}

The results of the current citizen-engaged research agenda-setting process identified four investigative priorities for mental health and nutrition that included programmes and services, service provider roles, the determinants of health, and knowledge translation and exchange that aims to identify effective models of care, enhance service collaboration, inform policy and foster knowledge dissemination. Second, this process identified research priority criteria that included appropriateness, relevancy, chance of success and impact of research outcome. Third, the agenda set out guidelines for research initiatives that included being applied and pragmatic, inclusive and equity-focused, fostering mental health literacy and being interdisciplinary. Finally, the citizenengaged process that was employed facilitated learning about setting research priorities related to mixed methods, engagement of diverse stakeholders and knowledge dissemination processes. 


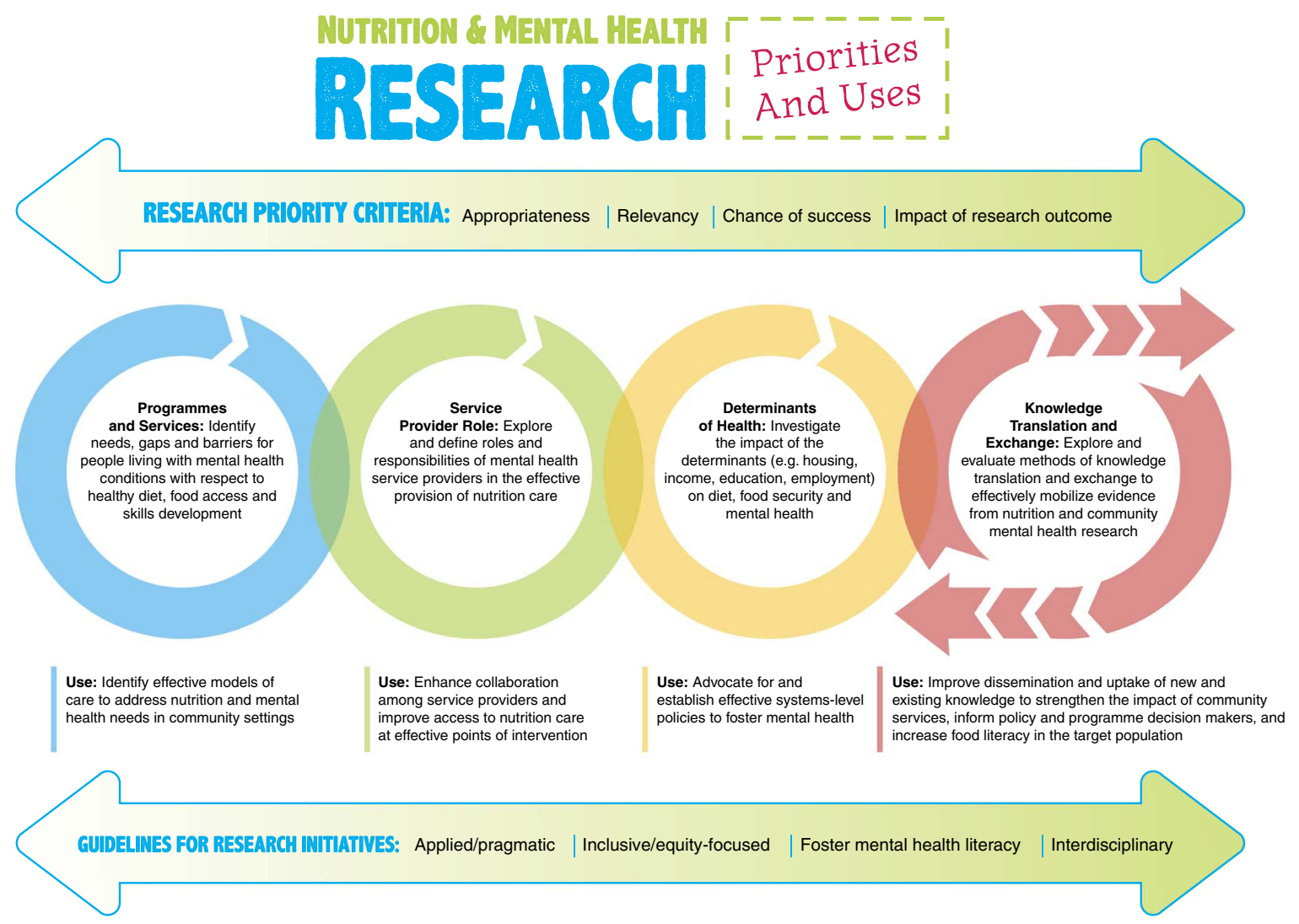

Fig. 1 (colour online) Conceptual framework of Canadian nutrition and mental health research agenda

\section{Use of mixed methods in research agenda-setting}

The present project was the first to apply citizen-engaged and mixed methods to establish a nutrition and mental health research agenda. The process, which involved a complex stakeholder community, resulted in a wideranging research agenda aimed at multiple levels and cross-sectoral collaboration $^{(41)}$. The use of mixed methods enabled a logical and progressive sequence of activities from the identification of research questions, the prioritization by diverse stakeholders, to more complex activities of prioritizing the questions using specified criteria - that enhanced understanding of what was valued by different stakeholders. A surprising result was the number of responses to the online survey from participants who identified themselves as having mental health issues. This outcome may have been due to the use of different means of engagement (e.g. online, telephone interviews) which fostered involvement by alleviating the effects of stigma $^{(42)}$. Finally, the results indicated that no individual topic scored consistently across all measures, stakeholders and procedures, suggesting that while research priorities should be set broadly they may also need to be tailored according to the stakeholders involved.

\section{Effects of citizen engagement on research agenda- setting}

As the literature suggests, engaging 'experts by experience' supports empowerment and can lead to improved services $^{(43)}$. Our findings were consistent with others that indicate individuals with lived experience are capable of research prioritization and that citizen engagement can help foster sharing of practical and conceptual knowledge among stakeholders $^{(44,45)}$, broaden research agendas ${ }^{(42,43,46)}$ and lead to improved quality and external validity of research ${ }^{(47,48)}$.

Stakeholders with lived experience of mental health issues (personally or through family members) tended to differ from the core group by prioritizing research questions aimed at promoting mental health or preventing or delaying the onset of mental health conditions. This may suggest that individuals with lived experience of a mental health condition recognize the value of focusing on mental health promotion and upstream prevention.

Some lessons were learned that could help with future initiatives. For example, further success may have occurred if focus groups with individuals who have mental health conditions were conducted or by having peer research assistants help recruit potential respondents, as direct and repeated engagement of affected individuals can facilitate and enhance debate about research ${ }^{(49,50)}$. Furthermore, an ongoing challenge will be to sustain collaboration among stakeholders.

\section{Perspectives on knowledge dissemination}

An important process learning outcome was the identified need for integrated knowledge translation. In recent years, a number of studies have been done in nutrition and 
mental health; however, stakeholders at the national workshop identified that the uptake of this knowledge has been limited. This issue has been identified by others who suggest that knowledge translation models that function in a unidirectional manner from researchers to stakeholders limit the uptake of empirically supported treatments, lead to gaps between research and its application, and result in reduced returns in public funds invested in research ${ }^{(51,52)}$. To address these challenges, integrated models of knowledge dissemination involving enhanced reciprocal exchanges and collaboration between researchers and stakeholders are needed $^{(52-54)}$. For example, consultation with diverse stakeholders enabled us to adjust the research agenda to include knowledge translation and exchange as a priority as it was identified as a practical issue that exists in nutrition and mental health systems.

\section{Limitations}

Some limitations to our approach must be noted. The response rate for the key informant survey was conservative and this was likely due to the proximity in timing around the winter holidays. Although the population involved was relatively diverse, a larger sample size within certain subsets (e.g. post-secondary students) may have extended the findings. It is difficult to judge how representative of the broader community the online survey sample was as recruitment focused on established networks of the advisory committee. In addition, it cannot be determined if the slight differences in research priorities between the online survey and stakeholder workshop can be attributed to the influence of decision making of those with lived experience or simply because of the absence or presence of defining criteria. However, the research agenda emerged from different processes, did not attach emphasis on a single method and aligned with the investigative gaps found from the scoping review.

Other limitations include the challenges that participants identified. Respondents believed that research uptake will be hindered if results pointed to a need for increased allocation of public funds to address mental health. Without policy support, such research endeavours may be deterred. There is also concern about the underfunding of community-based research and limited interest for addressing nutrition and mental health due to associated stigmas and scepticism regarding outcomes. Finally, while the development of an agenda is important to providing investigative directions, it must also be stressed that the final product will be defined by underlying contextual assumptions. In particular, an issue to consider is how nutrition (e.g. diet quality, food insecurity, nutrient intakes) and mental health (e.g. psychiatric symptoms, condition, general mental well-being) are defined in studies and the subsequent interpretation, generalizability and transference of the results.

\section{Conclusion}

A recent expert consensus statement on research needs in mental health emphasized that protective factors should be prioritized when planning future research strategies ${ }^{(55)}$. Optimal nutrition is one fundamental determinant that can help prevent or reduce vulnerability to mental ill health. As the nutrition and mental health evidence continues to evolve, it faces challenges such as increasing health-care costs, limited public investments aimed at health equity ${ }^{(56)}$ and the implementation of various service delivery models. These barriers have made the establishment of nutrition and mental health research priorities increasingly critical and highlight the need to create meaningful research agendas that involve diverse stakeholders.

The outcomes of this research agenda that used citizenengaged and mixed-method approaches included four investigative priorities aimed at programmes, services, provider roles, the determinants of health and knowledge uptake, which can help identify effective models of care, develop policy and foster effective knowledge dissemination. Based on our experiences, we recommend the following to others to consider when developing research agendas: (i) engage diverse stakeholders from project conceptualization; (ii) utilize mixed methods of data collection to enable breadth and depth of understanding of the issues; and (iii) include different options for stakeholder engagement. Research agendas are an opportunity to bring awareness to issues, direct investigative efforts and provide a basis for funding development and allocation. Because research agendas are living documents that develop as part of contextual factors, all stakeholders need to support their development, actively apply them and participate in their evolution.

\section{Acknowledgements}

Acknowledgements: The authors would like to thank Tony Zhang for his assistance in the scoping review and the advisory committee members for their insights and directions on this project: Shana Calixte (Executive Director, Northern Initiative for Social Action); Mike Gawliuk (Director of Service Delivery and Program Innovation, Canadian Mental Health Association, Kelowna); Linda Greene-Finestone (Nutrition Advisor and Epidemiologist, Public Health Agency of Canada); Nick Kates (Chair and Professor, Psychiatry and Behavioural Neurosciences and Associate Member, Department of Family Medicine, McMaster University, Director of Programs, Hamilton Family Health Teams); Craig Larsen (Executive Director, Chronic Disease Prevention Alliance of Canada); Vikki Madden (Occupational Therapist, Guelph ACT Team, Homewood Health Centre); Lynette McGarrell (Dietitian, Mental Health Program: Eating Disorders Clinic, Halton Healthcare Services); Eric Ng (Dietitian, Public Health 
Ontario); and Nandini Saxena (Manager, Knowledge Exchange, Centre for Addiction and Mental Health). Financial support: Financial support for this project was obtained from a Meetings, Planning and Dissemination Grant from the Canadian Institutes of Health Research (reference number 127193) and by in-kind contributions from the Canadian Mental Health Association (Ontario), Dietitians of Canada and the University of British Columbia, School of Nursing. The funders had no role in the design, analysis or writing of this article. Conflict of interest: The authors have no financial conflicts of interest to declare. Authorship: All authors contributed to the project's design and implementation. C.D. wrote the project summary reports. K.M.D. drafted the manuscript based on the findings of the reports. All authors contributed to the final draft. Ethics of buman subject participation: This study was approved by the University of British Columbia Behavioural Research Ethics Board.

\section{References}

1. Mehta N, Croudace T \& Davies SC (2015) Public mental health: evidence-based priorities. Lancet $\mathbf{3 8 5}$, $1472-1475$.

2. US Department of Agriculture (2015) Scientific Report of the 2015 Dietary Guidelines Advisory Committee (Advisory Report). Washington, DC: USDA.

3. World Health Organization (2008) The Bamako Call to Action on Research for Health: Strengthening Research for Health, Development, and Equity. Geneva: WHO.

4. Goyet S, Touch S, Ir P et al. (2015) Gaps between research and public health priorities in low income countries: evidence from a systematic literature review focused on Cambodia. Implement Sci 10, 32.

5. Gabbay J \& Le May A (2004) Evidence based guidelines or collectively constructed 'mindlines?' Ethnographic study of knowledge management in primary care. BMJ 329, 1013.

6. Wieringa S \& Greenhalgh $\mathrm{T}$ (2015) 10 years of mindlines: a systematic review and commentary. Implement Sci 10, 45.

7. Davison KM, Ng E, Chandrasekera U et al. (2012) Promoting Mental Health through Healthy Eating and Nutritional Care. Toronto, ON: Dietitians of Canada.

8. Whiteford HA, Degenhardt L, Rehm J et al. (2013) Global burden of disease attributable to mental and substance use disorders: findings from the Global Burden of Disease Study 2010. Lancet 383, 1575-1586.

9. Vos T, Flaxman AD, Naghavi M et al. (2012) Years lived with disability (YLDs) for 1160 sequelae of 289 diseases and injuries 1990-2010: a systematic analysis for the Global Burden of Disease Study 2010. Lancet 380, 2163-2196.

10. Lim SS, Vos T, Flaxman AD et al. (2012) A comparative risk assessment of burden of disease and injury attributable to 67 risk factors and risk factor clusters in 21 regions, 1990-2010: a systematic analysis for the Global Burden of Disease Study 2010. Lancet 380, 2224-2260.

11. Tomlinson M, Rudan I, Saxena S et al. (2009) Setting priorities for global mental health research. Bull World Health Organ 87, 438-446.

12. Sarris J, Logan AC, Akbaraly TN et al. (2015) Nutritional medicine as mainstream in psychiatry. Lancet Psychiatry $\mathbf{2}$, 271-274.
13. Keeney S, Hasson F \& McKenna H (2011) Debates, criticisms and limitations of the Delphi. The Delphi Technique in Nursing and Health Research, pp. 18-31. Oxford: Wiley-Blackwell.

14. Mitroff II \& Turoff M (1975) Philosophical and methodological foundations of Delphi. In The Delphi Method: Techniques and Applications, pp. 17-35 [HA Linstone and M Turoff, editors]. Reading, MA: Addison-Wesley Publishing Company.

15. van Bon-Martens MJ, van de Goor LA, Holsappel JC et al. (2014) Concept mapping as a promising method to bring practice into science. Public Health 128, 504-514.

16. Drake RE \& Whitley R (2014) Recovery and severe mental illness: description and analysis. Can J Psychiatry 59, 236-242.

17. Creswell JW \& Plano Clark VL (2011) The nature of mixed methods research. Designing and Conducting Mixed Methods Research, 2nd ed. pp. 1-18. Thousand Oaks, CA: SAGE Publications, Inc.

18. Lavis JN, Robertson D, Woodside JM et al. (2003) How can research organizations more effectively transfer research knowledge to decision makers? Milbank $Q$ 81, 221-248.

19. Eisenberg JM (2002) Globalize the evidence, localize the decision: evidence-based medicine and international diversity. Health Aff (Millwood) 21, 166-168.

20. National Institute of Mental Health (1999) Bridging Science and Service: A Report by the National Advisory Mental Health Council's Clinical Treatment and Services Research Workgroup. Washington, DC: National Institute of Mental Health.

21. Partnerships and Citizen Engagement Branch, Canadian Institutes of Health Research (2012) CIHR's Framework for Citizen Engagement. http://www.cihr-irsc.gc.ca/e/41270. html (accessed May 2016).

22. Henderson J, Brownlie E, Rosenkranz S et al. (2013) Integrated knowledge translation and grant development: addressing the research practice gap through stakeholderinformed research. J Can Acad Child Adolesc Psychiatry 22, 268-274.

23. Drake RE \& Latimer E (2012) Lessons learned in developing community mental health care in North America. World Psychiatry 11, 47-51.

24. Lehman AF, Kreyenbuhl J, Buchanan RW et al. (2004) The Schizophrenia Patient Outcomes Research Team (PORT): updated treatment recommendations 2003. Schizophr Bull 30, 193-217.

25. Solomon P (2004) Peer support/peer provided services underlying processes, benefits, and critical ingredients. Psychiatr Rehab J 27, 392-401.

26. Culhane D (2008) The costs of homelessness: a perspective from the United States. Eur J Homelessness 2, 97-114.

27. Larimer M, Malone D \& Garner M (2009) Health care and public service use and costs before and after provision of housing for chronically homeless persons with severe alcohol problems. JAMA 301, 1349-1357.

28. Latimer E (1999) Economic impacts of assertive community treatment: a review of the literature. Can J Psychiatry, 1999 44, 443-454.

29. Mental Health Commission of Canada (2013) Making the Case for Investing in Mental Health in Canada. Calgary, AB: Mental Health Commission of Canada.

30. Fixsen D, Naoom S \& Blase K (2005) Implementation Research: A Synthesis of the Literature. Tampa, FL: University of South Florida.

31. Rapp C, Etzel-Wise D \& Marty D (2008) Evidence-based practice implementation strategies: results of a qualitative study. Community Ment Health J 44, 213-224.

32. D'Andreamatteo C, Davison KM, Mitchell S et al. (2015) Dietitians and Community Mental Health: Setting the Research Agenda. Toronto, ON: Dietitians of Canada; available at http://www.dietitians.ca/Downloads/Public/ 2015-Dietitians-and-Community-Mental-Health-Resear.aspx 
33. Anderson S, Allen P, Peckham S et al. (2008) Asking the right questions: scoping studies in the commissioning of research on the organisation and delivery of health services. Health Res Policy Syst 6, 7.

34. Whittemore R, Chao A, Jang M et al. (2014) Methods for knowledge synthesis: an overview. Heart Lung 43, 453-461.

35. American Psychiatric Association (2013) Diagnostic and Statistical Manual of Mental Disorders, Fifth Edition. Arlington, VA: APA Publishing.

36. Jones S, Murphy F, Edwards M et al. (2008) Using online questionnaires to conduct nursing research. Nurs Times 104, 66-69.

37. Fluidware (2014) FluidSurveys ${ }^{\mathrm{TM}}$ - Canadian Survey Software. http://fluidsurveys.com (accessed May 2016).

38. Braun V \& Clarke V (2006) Using thematic analysis in psychology. Qual Res Psychol 3, 77-101.

39. Okello D \& Chongtrakul P (2000) A Manual for Research Priority Setting using the ENHR Strategy. Geneva: The Council on Health Research for Development.

40. D'Andreamatteo C \& Zhang T (2013) Dietitians and Community Mental Health: Setting the Research Agenda: Scoping Review. Toronto, ON: Dietitians of Canada.

41. The Mental Health Commission of Canada, Eclarin $\mathrm{T} \&$ Mackinnon MP (2013) Case 2: Engaging Canadians in the Development of a Mental Health Strategy for Canada. Ottawa, ON: Canadian Institutes of Health Research; available at http://www.cihr-irsc.gc.ca/e/47589.html

42. World Health Organization (2010) User Empowerment in Mental Health - A Statement by the WHO Regional Office for Europe. Copenhagen: WHO Regional Office for Europe.

43. Caron-Flinterman JF, Broerse JE, Teerling J et al. (2005) Patients' priorities concerning health research: the case of asthma and COPD research in the Netherlands. Health Expect 8, 253-263.

44. Walter I, Davies H \& Nutley S (2003) Increasing research impact through partnerships: evidence from outside health care. J Health Serv Res Policy 8, Suppl. 2, 58-61.
45. Oliver S, Clarke-Jones L, Rees R et al. (2004) Involving consumers in research and development agenda setting for the NHS: developing an evidence-based approach. Health Technol Assess 8, 1-148, III-IV.

46. Nierse CJ, Abma TA, Horemans AM et al. (2013) Research priorities of patients with neuromuscular disease. Disabil Rehabil 35, 405-412.

47. Herschell AD, McNeil CB \& McNeil DW (2004) Clinical child psychology's progress in disseminating empirically supported treatments. Clin Psychol Sci Pract 11, 267-288.

48. Bartunek J, Trullen J, Bonet E et al. (2003) Sharing and expanding academic and practitioner knowledge in health care. J Health Serv Res Policy 8, Suppl. 2, 62-68.

49. Trede F (2012) Emancipatory physiotherapy practice. Physiother Theory Pract 28, 466-473.

50. McHugh RK \& Barlow DH (2010) The dissemination and implementation of evidence-based psychological treatments: a review of current efforts. Am Psychol 65, 73-84.

51. Canadian Institutes of Health Research, Institute of Neurosciences, Mental Health and Addiction (2006) Strategic Plan 2007-2011. Ottawa, ON: CIHR, INMHA.

52. Becker CB, Stice E, Shaw H et al. (2009) Use of empirically supported interventions for psychopathology: can the participatory approach move us beyond the research-topractice gap? Behav Res Ther 47, 265-274.

53. Bowen S \& Martens S (2005) Demystifying knowledge translation: learning from the community. J Health Serv Res Policy 10, 203-211.

54. Graham ID, Logan J, Harrison MB et al. (2006) Lost in knowledge translation: time for a map? J Contin Educ Health Prof 26, 13.

55. Forsman AK, Wahlbeck K, Aarø LE et al. (2015) Research priorities for public mental health in Europe: recommendations of the ROAMER project. Eur J Public Health 25, 249-254.

56. Muzyka D, Hodgson G \& Prada G (2012) The Inconvenient Truths About Canadian Health Care: A Briefing from the Summit on Sustainable Health and Health Care. Ottawa, ON: The Conference Board of Canada. 